\section{SínDROME CISTOCEREBRAL}

\section{Cystocerebral Syndrome}

Sr. Editor: El síndrome confusional agudo (SCA), o delirium, consiste en una alteración cognitiva abrupta, que se da principalmente en mayores de 65 años ${ }^{1}$. Entre 10\% y 30\% de los ancianos presentan delinio en el Departamento de Emergencias, y hasta 55\% de los que se inteman en salas quirúrgicas ${ }^{1}$. Aunque el SCA se considere un cuadro reversible, a menudo representa una señal de un futuro deterioro de las funciones cognitivas. Su mecanismo fisiopatológico no es bien conocido; se postula que, sobre factores predisponentes (edad avanzada, deterioro cognitivo, entre otros $)^{1}$, actúan desencadenantes múltiples, de distinta naturaleza. Está demostrado que este cuadro aumenta la estadía hospitalaria, así como la mortalidad a 6 y 12 meses y la institucionalización en pacientes ancianos ${ }^{1}$. Se denomina síndrome cistocerebral (SC) a la aparición del SCA en el contexto de una retención aguda de orina, con resolución completa luego de la desobstrucción de la vía uninaria ${ }^{2,3}$.

Un paciente de sexo masculino, de 83 años, con antecedentes de hipertensión arterial, cardiopatía isquémica, accidente cerebrovascular isquémico con infarto en territorio de arteria cerebral posterior derecha y paresia braquiocrural izquierda residual, y litiasis vesical, ingresó por presentar SCA (delinio hiperactivo) asociado a oligoanuria. Al intermogatorio indirecto, no presentaba fiebre o equivalentes, síntomas urinarios asociados, o cambios en su medicación habitual. No era fumador ni etilista. Al ingresar estaba normotenso, con frecuencia cardíaca de 80 latidos por minuto, frecuencia respiratoria de 16 por minuto, $\mathrm{SaO}_{2} 97 \%$ al aire ambiente. Presentó las cuatro variables alteradas del "Confusion Assessment Method" (CAM), paresia braquiocrural izquierda residual, sin otros hallazgos en el examen neurológico. Presentó examen cardiaco y respiratorio sin particularidades, puño-percusión renal bilateral negativa $\mathrm{y}$ abdomen indoloro. Dado el antecedente de oligoanuria, se colocó sonda vesical, con débito de 900 ml. El cuadro de confusión se resolvió en la hora subsiguiente. Se tomaron hemocultivos y urocultivos, que fueron negativos; el laboratorio no eviden-

Correspondencia a: Dr. Pablo Young.

E mail: pabloyoung2003@yahoo.com.ar ció alteraciones (hemograma, hepatograma, glicemia, coagulograma, creatininemia, uremia, ionograma, calcemia, fósforo, magnesio, amonio, creatinfosfoquinasa, velocidad de sedimentación globular, proteína $\mathrm{C}$ reactiva, función tiroidea, $\mathrm{y}$ sedimento urinario). La tomografía axial computada de cerebro mostró una secuela isquémica en el temitorio de la cerebral posterior y el electroencefalograma presentó lentificación difusa. El paciente evolucionó favorablemente, egresando al segundo día de intemación con sonda vesical y posterior control en consultorios extemos.

En 1990, Blackbum y Dunn ${ }^{2}$ describieron tres pacientes con delirium que presentaron retención aguda de orina. Los tres casos tenían edad cercana a los 70 años, antecedentes de hiperplasia prostática benigna y ausencia de dolor abdominal. Tuviemon resolución completa de los síntomas neurológicos después de la desobstrucción de la vía urinaria, lo que fue denominado por los autores como SC.

Posteriormente, Liem y Carter ${ }^{3}$ propusieron que el aumento de la tensión parietal en la vejiga, secundaria a la retención de orina por algún mecanismo obstructivo, produciría un aumento en el tono adrenérgico, tanto a nivel central como periférico. Esto desencadenaría un disbalance a nivel central de neurotransmisores colinérgicos y adrenérgicos, dando como resultado un $\mathrm{SCA}^{3}$.

Sin embargo, existen numerosos factores asociados a la retención aguda de orina que pueden vincularse al delirium, que deben ser descartados. Entre ellos, cabe mencionar la infección urinaria, así como la insuficiencia renal. En el caso de los pacientes descriptos inicialmente por Blackburn y Dunn, así como en nuestro paciente, dichos elementos estuvieron ausentes.

Como causas y factores precipitantes del SCA se han descripto desórdenes neurológicos agudos primanios (infecciosos, vasculares, traumáticos, eléctricos, neoplásicos, inflamatorios y vasculíticos), desórdenes sistémicos (metabólicos, nutricionales, endocrinos, infecciosos) y otros extrínsecos, como drogas (tanto el abuso como su abstinencia), algunas toxinas, el dolor, constipación y, en el caso que nos ocupa, la retención uninaria ${ }^{4,5}$. Se puede usar para el diagnóstico el CAM, que consta de 4 variables: 1) comienzo agudo y fluctuante; 2) inatención; 3) pensamiento desorganizado; y 4) alteración del nivel de conciencia ${ }^{4}$. El acercamiento al paciente confuso debe constar de una historia clínica comprensiva y examen físico, que 
incluya pruebas cognitivas, control riguroso de las medicaciones y hábitos del paciente (es bien conocido el delino del paciente intemado por abstinencia al alcohol o nicotina), análisis de laboratono básicos, búsqueda de infección oculta (urocultivo, hemocultivo y radiografía de tórax) y otros estudios de acuerdo al caso (análisis como amonio sanguíneo, homonas tiroideas, vitamina B12, toxicológico, gases sanguíneos, punción lumbar, tomografía o resonancia de cerebro, electroencefalograma) ${ }^{5}$. Este último estudio lo utilizamos de rutina en los pacientes confusos encontrando muchos con status epiléptico no convulsivo, expeniencia publicada recientemente por nuestro grupo ${ }^{6}$. Se ha demostrado que el SCA puede ser prevenido adoptando ciertas medidas de intervención, como el diagnóstico temprano de detenioro cognitivo, de alteraciones visuales o auditivas y evitar la deprivación de sueño, la inmovilidad y deshidratación, entre otras $^{5}$. El tratamiento más efectivo es solucionar la causa subyacente.

El SC es, por lo tanto, una causa identificable de delirium, se debe sospechar en pacientes con antecedentes de trastomos urológicos, como hiperplasia prostática benigna u otras causas de obstrucción de la vía urinaria, ya que presenta tratamiento rápido y efectivo.

Pablo Young, Juan S. Lasa, Bárbara C. Finn, Mariano Quezel, Julio E. Bruetman

Servicio de Clínica Médica, Hospital Británico de Buenos Aires

\section{REFERENCIAS}

1. Ferreyra A, Belletti G, Yorio M. Síndrome confusional agudo en pacientes internados. Medicina (Buenos Aires) 2004; 64: 385-9.

2. Blackburn T, Dunn J. Cystocerebral syndrome. Acute urinary retention presenting as confusion in elderly patients. Arch Intern Med 1990; 150: 2577-8.

3. LEM PH, CARTER WL Cystocerebral syndrome: A possible explanation. Arch Intern Med 1991; 151: 1884-5.

4. Inouye SK, van Dyck CH, Alessi CA, Balkin S, Siegal AP, Horwitz RI. Clarifying confusion: The confusion assessment method. Ann Intern Med 1990; 113: 941-8.

5. Johnson MH. Assessing confused patients. J Neurol Neurosurg Psychiatry 2001; 71: 7-12.

6. Bottaro FJ, Martínez OA, Pardal MM, Bruetman JE, Reisin RC. Nonconvulsive status epilepticus in the eldenly: a case-control study. Epilepsia 2007; 48: 966-72.

\section{¿Qué es Medicina Interna?}

\section{What is Internal Medicine?}

Sr. Editor: Gracias por el artículo sobre la definición de Medicina Interna, publicado en la Revista Médica de Chile ${ }^{1}$. Es muy difícil para quienes ejercemos esta especialidad poder definir con claridad al público nuestro trabajo, cuando es tan importante e implica muchos sacrificios. Su artículo es muy abarcador y nos lleva a explorar los orígenes del término y su evolución. Nos inspira y nos guía para trasladar ese conocimiento de la historia a nuestros estudiantes de medicina y residentes. Comparto el aprecio que tenemos a nuestra especialidad, tan digna pero muchas veces no tan reconocida. Su artículo me sirvió en un programa de televisión en Puerto Rico, de la Cadena del Gobierno, para explicar a los televidentes lo que es un internista, y la definición que usted expone es la más precisa que he leído. Yo sólo le añadí que somos "los pediatras de los adultos".

Es interesante constantar que el problema de identidad de la Medicina Interna no es local sino mundial, pero la vocación que la mueve es una de las más genuinas que conozco.

\section{Elsie I Cruz Cuevas, MD, FACP}

Profesora Asociada de Medicina Interna

Universidad de Puerto Rico

\section{REFERENCIAS}

1. REYES H. ¿Qué es Medicina Interna? Rev Méd Chile 2006; 134: 1338-44.

Correspondencia a: Elsie I. Cruz Cuevas, MD FACP. Universidad de Puerto Rico, Recinto de Ciencias Médicas. Puerto Rico. E mail: eicruz@yahoo.com 